\title{
Programa de apoyo para el grupo "Cocineras Unidas" de la comunidad de Palo Blanco, Municipio de Tamiahua, Ver.
}

Support program for the group "Cocineras Unidas" from the community of Palo Blanco, Municipality of Tamiahua, Ver.

Hidalgo Barrios Blanca Vianey ${ }^{1 \bowtie}$, Hernández Zamora Honoria ${ }^{1}$, Pineda Moreno Araceli ${ }^{1}$, Gómez

Priego Alejandra Ilean ${ }^{1}$, Camacho Díaz Othón Darío ${ }^{1}$

1 Facultad de Contaduría. Campus Tuxpan. Universidad Veracruzana

$\bowtie$ Autor para correspondencia: vbarrios@ hotmail.com

Recibido: $15 / 07 / 2017$

Aceptado: 10/12/2017

\section{RESUMEN}

Este proyecto de investigación tiene como objetivo contribuir a impulsar la productividad de las mujeres emprendedoras mayores de 18 años, que habitan en los Núcleos Agrarios del país, que conozcan que existen programas que mediante el otorgamiento de incentivos pueden llegar a realizar proyectos productivos. La operación del Programa para productividad de la mujer emprendedora (PROMETE), es de conformidad a lo establecido por las reglas de operación que emite la SAGARPA, las convocatorias son publicadas en cada ejercicio fiscal, con la finalidad de hacer más eficiente y eficaz la gestión pública y brindar un mejor servicio a la población objetivo del componente en mención. En la investigación se realizaron entrevistas al técnico asesor y a las integrantes de grupo cocineras unidas, quienes coinciden en que la asimilación del proyecto como propio, la asesoría y el acompañamiento son aspectos clave para la supervivencia de los proyectos.

Palabras clave: PROMETE, Proyectos productivos, Mujeres emprendedoras

\begin{abstract}
This research project aims to contribute to boost the productivity of women entrepreneurs over 18 years of age, who live in the Agrarian Nuclei of the country, who know that there are programs that through the granting of incentives can achieve productive projects. The operation of the Entrepreneurial Women Productivity Program (PROMETE), is in accordance with the rules of operation issued by SAGARPA, the calls are published in each fiscal year, in order to make management more efficient and effective public service and provide a better service to the target population of the mentioned component. The research carried out interviews with the technical advisor and the members of the united cook group, who agree that the assimilation of the project as its own, the advice and the accompaniment are key aspects for the survival of the projects.
\end{abstract}

Key words: PROMETE, Productive projects, Entrepreneurial women. 


\section{INTRODUCCIÓN}

Actualmente la generación del empleo se da mediante los proyectos productivos que brinda apoyos para el incremento en la productividad total de los factores y en la productividad laboral; en ventas; en uso de tecnologías; en posicionamiento en el mercado; en acceso a financiamiento y a nuevos mercados; en incremento de la calidad de los productos, procesos y/o servicios; una mayor cobertura y mayor facilidad para hacer negocios. (Programas de financiamiento, asesoría, apoyo y certificación)

El Programa de Apoyo para la Productividad de la Mujer Emprendedora (PROMETE) es una política pública a favor de las mujeres que tienen por objeto fomentar la igualdad de oportunidades y de trato a las mujeres rurales y promover el ejercicio pleno de sus derechos para dar cabal cumplimiento a lo establecido en los artículos 1 y 4 de la Constitución Política de los Estados Unidos Mexicanos, la Convención sobre la Eliminación de Todas las Formas de Discriminación contra la Mujer (CEDAW), la Comisión Económica Para América Latina (CEPAL) y los artículos 1, 2 y 3 de la Ley General para la Igualdad entre Mujeres y Hombres (LGIMH) (dof.gob.mx).

Este tipo de apoyos son otorgados a través de convocatorias públicas emitidas por SAGARPA en este caso, tiene una cobertura nacional y se dirige a personas que habitan en núcleos agrarios y tienen como finalidad la implementación de unidades productivas de grupos de trabajo o figuras legalmente constituidas, cuyos integrantes tienen visión de crecer a corto plazo y consolidarse a mediano y largo plazo, buscando impulsar la integración productiva de hombres y mujeres para desarrollar actividades generadoras de empleos e ingresos, así como a través de la capacitación, detonar el desarrollo de capacidades y habilidades emprendedoras. (sagarpa .gob, 2016).

La mujer emprendedora, caracterizada por un espíritu activo y positivo, que la lleva a asumir riesgos y compromisos, desafía al mercado y al sistema, se levanta y vuelve a empezar asumiendo los inconvenientes y fracasos como aprendizajes. Es esta mujer la que con valentía ha sabido enfrentar la crisis terrible que vivimos hoy en día. El autoempleo constituye, en muchos casos, la única oportunidad de la que disponen muchas mujeres para ganar un ingreso de subsistencia, debido a que el empleo se encuentra muchas veces fuera de su alcance.

El desarrollo de actividades emprendedoras no es fácil y vuelven a demostrar el ingenio y la capacidad de trabajo que estas mujeres, algunas como único sostén de sus familias, demuestran que son capaces al sortear las múltiples dificultades que se le presentan. (gestipolis.com).

\section{MATERIALES Y MÉTODOS}

El procedimiento y tramitación para la obtención del fondo de apoyo a proyectos productivos en núcleos agrarios (FAPPA) y el programa de apoyo para la productividad de la mujer emprendedora (PROMETE), para el grupo "Cocineras Unidas" de la Comunidad de Palo Blanco perteneciente al municipio de Tamiahua, Ver.; se realizó mediante una serie de pasos que fueron llevados a cabo por el grupo beneficiario de la cocina económica y la asesoría de un técnico asignado por la SAGARPA. 
A continuación se explica a detalle cada uno de estos trámites realizados por el grupo cocineras unidas para la obtención del programa de apoyo, el cual es ejecutado por la Secretaría de Agricultura, Ganadería, Desarrollo Rural,

Pesca y Alimentación (SAGARPA), dependencia del Poder Ejecutivo Federal. Este programa está sujeto a las reglas de operación según lo establece el Decreto de Presupuesto de Egresos de la Federación para el ejercicio fiscal 2016:

\section{Cubrir los siguientes requisitos.}

Habitar en un "Núcleo Agrario" del país, conforme al Padrón e Historial de Núcleos Agrarios (PHINA) del Registro Agrario Nacional (RAN).

Tener 18años cumplidos o más, al momento de ingresar la Solicitud de Apoyo.

-

Constituirse en cualquiera de sus dos modalidades:

Sin formalidad jurídica, integrados con un mínimo de tres y hasta seis integrantes;

-

Legalmente constituidas, con un mínimo de tres y sin límite máximo de integrantes.

No haber sido apoyadas en los últimos cinco ejercicios fiscales por el mismo Programa antes PROMUSAG ahora PROMETE y por el FAPPA; a excepción de las solicitudes para ampliación o escalamiento.

\section{Elaboración de las solicitudes de apoyo y} recopilación de la documentación solicitada.

La solicitud de apoyo FAPPA-PROMETE del SICAPP es el anexo LXX, el cual debe ser llenado con los requisitos que solicita SAGARPA en ventanilla y firmado por el grupo
"Cocineras Unidas". De igual forma se adjunta la siguiente documentación:

Formulación del Proyecto Productivo FAPPA-PROMETE" Anexo LXXI;

Identificación oficial con fotografía de cada integrante, en la que se especifique el domicilio registrado en el SICAPP, en caso de que esta no precise el Núcleo

Agrario registrado, adicional y obligatoriamente deberá presentar la Constancia de Residencia expedida por Comisariado Ejidal o de Bienes Comunales.

-

Acta de Asamblea de constitución del grupo.

-

Fotografía de los integrantes del grupo, acompañado del Asesor Técnico en el domicilio registrado y en el lugar donde se instalará el proyecto.

Croquis de Macro y Micro localización del proyecto.

-

Acuerdo de Voluntades firmado por el Grupo, para que a nombre del Grupo sean los responsables del cobro de la orden de pago.

口

Escrito que manifieste cada integrante no ser solicitante de apoyo en otro programa del gobierno con proyectos productivos.

\section{Focalización por marginación y vulnerabilidad.}

Los mecanismos de focalización requieren de un instrumento que permita discriminar la situación de pobreza o riesgo social de una persona, de un hogar o de una unidad productiva que demanda los beneficios de un programa o servicio. El mecanismo supone que los integrantes del grupo destinatario se acercarán al servicio o programa y demandarán sus beneficios.

Sólo los recibirán las unidades que califican de pobre o en riesgo social, el resto no es atendido 
o es atendido mediando un copago. Esta forma de focalización privilegia una relación individual del beneficiario con el programa o servicio.

\section{Autorización de solicitudes de apoyos}

Una vez aplicado el análisis de focalización por marginación y vulnerabilidad y con base en la disponibilidad presupuestal de los componentes FAPPA y PROMETE, se someterán a autorización del Comité Técnico aquellas solicitudes de apoyo que resulten técnicamente procedentes y se hará llegar la respuesta vía correo al asesor técnico en forma de invitación, donde se le informa que el proyecto fue aprobado.

\section{Inducción a grupos autorizados}

Sesión Informativa que permite a los Beneficiarios acceder a un espacio de enseñanza-aprendizaje, proporcionándoles herramientas teóricas y/o prácticas.

Para recibir la capacitación deberá presentarse al menos el $80 \%$ de los integrantes del Grupo Beneficiario, para lo cual se requiere que cada uno de los asistentes presente original de una identificación oficial con fotografía.

-

Asimismo, el Grupo Beneficiario deberá entregar el Contrato de Asesoría debidamente integrado y firmado.

\section{Convenio de concertación}

Tiene por objeto establecer los derechos y obligaciones de las partes, así como, fijar las bases de concertación para conjuntar acciones y en su caso, recursos para la implementación del "Proyecto Productivo". Se deberá presentar lo siguiente:

Original y copia de sus identificaciones oficiales vigentes con fotografía
Contrato de Asesoría Técnica Anexo LXXII en tres tantos.

-

Copia simple de la identificación oficial con fotografía $y$ firma del Asesor Técnico.

Carta Intención para acreditar la posesión, propiedad o derecho del uso del inmueble donde se desarrollará el Proyecto Productivo.

\section{Informe general de la aplicación del} recurso

El Grupo Beneficiario asume el compromiso de presentar el Informe General de la Aplicación del Recurso Anexo LXXIII a los 60 días naturales posteriores a la fecha de recepción de la Orden de Pago Referenciada.

\section{Verificaciones de proyectos productivos:}

Una vez liberado el recurso para llevar a cabo el proyecto se realiza las siguientes supervisiones:

Supervisión de Puesta en Marcha: Es la inspección documental y de campo que se realiza a los Grupos Beneficiarios a partir de los 60 días naturales de haber recibido la orden de pago referenciada con el monto del apoyo solicitado y cuya finalidad es verificar la integración del grupo, el grado de avance del proyecto productivo, la entrega del Informe General de la Aplicación del Recurso y el cumplimiento de la Asesoría Técnica.

Verificación de Seguimiento: Es la inspección documental y de campo que se realiza a los Grupos Beneficiarios del ejercicio fiscal anterior, cuya finalidad consiste en verificar la aplicación del recurso y la operación del proyecto productivo. 
Supervisión Especial: Es la inspección documental y de campo que se realiza cuando exista alguna queja o denuncia relacionada con un proyecto productivo.

El seguimiento del procedimiento descrito para la obtención del proyecto productivo del grupo Cocineras Unidas permitió tener resultados positivos, ya que se logró la estructuración e implantación del programa de apoyo, beneficiando a 6 familias de la comunidad Palo Blanco, generándoles mejores condiciones de vida y una participación activa en el ámbito económico

\section{CONCLUSIONES}

Es de especial interés conocer los proyectos que existen, cuáles son los requisitos para llevarlos a cabo, que este tipo de proyectos se otorga a mujeres emprendedoras con ganas de superación, para que puedan empezar a producir y generar ingresos para ellas y sus familias, además de contribuir en la generación de empleos a terceros.

Los procedimientos para la obtención del apoyo FAPPA-PROMETE se sujetan a las Reglas de Operación de los mismos, a sus Anexos y al Manual respectivo. El apoyo fue otorgado al grupo en los tiempos establecidos y una vez realizado el proceso de dispersión de los recursos a la información bancaria del beneficiario autorizado, se dio un término de 60 días naturales para verificar que fue realizado el depósito y posteriormente presentar el informe general de aplicación del recurso.

Este proyecto productivo es hoy una realidad que brinda apoyo al grupo de cocineras unidas de la comunidad de Palo Banco en Tamiahua, Veracruz. Un grupo de 6 mujeres de una zona marginada donde no se obtienen los ingresos necesarios para abastecerse de las necesidades como son: mantener a una familia, continuar con los estudios o simplemente tener un mejor futuro para sus hijos. La cocina económica hoy les genera a este grupo de mujeres emprendedoras sus propios recursos además de brindar sus servicios a los pobladores de la comunidad.

Así mismo la aplicación y generación de este tipo de proyectos con estas características, garantizan un beneficio directo sobre la población de escasos recursos y vulnerable al entorno, sobre todo al económico. Se destaca la importancia de estos recursos para la población que habita en el medio rural, ya que si emplea de manera adecuada, se tiene un impacto directo en la zona en que se aplica, asegurando así un mejor futuro económico en la región.

\section{LITERATURA CITADA}

Sagarpa .gob. (2016). Obtenido de sagarpa .gob: http://www.sagarpa.gob.mx/agricultura/ Programas/proagro/Normatividad/Docu ments/2016/Reglas_Operacion_2016_sa garpa_DOF_OFICIAL.pdf

DOF.gob.mx. (s.f.). Obtenido de dof.gob.mx: http://dof.gob.mx/DOFmobile/nota_deta lle_popup.php?codigo $=5341589$

Gestipolis.com. (s.f.). Obtenido de gestiopolis.com: https://www.gestiopolis.com/la-mujeremprendedora/

Ideas de negocios.com.ar. (s.f.). Obtenido de Ideas de negocios.com.ar: https://ideasdenegocios.com.ar/ventajasemprender-negocio-propio.htm

Programas de financiamiento, asesoría, apoyo y certificación. (s.f.). Obtenido de Programas de financiamiento, asesoría, apoyo y certificación: http://prolab.canacintraens.org/Modulo_ 5/index.html 
Copyright (c) 2017 Blanca Vianey Hidalgo Barrios, Honoria Hernández Zam or a, Araceli Pineda Moreno,

Alejandra Ilean Gómez Priego y Othón Dario Camacho Diaz

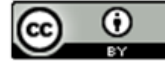

Este tex to está protegido por una licencia licencia Creative Commons 4.0 .

Usted es libre para Compartir —copiar y redistribuir el material en cualquier medio o form ato- y Adaptar el documento —remezclar, transformar y crear a partir del material- para cualquier propósito,, incluso para fines comerciales, siempre que cumpla la condición de:

Atribución: Usted debe dar crédito a la obra original de manera adecuada, proporcionar un enlace a la licencia, e in đicar si se han realizado cam bios. Puede hacerlo en cualquier form a razonable, pero no de form a tal que sugiera que tiene el apoyo del licenciante o 10 recibe por el uso que hace de la obra.

Resumendelicencia - Textocompletodelalicencia 